\title{
The role of clinical parapapillary atrophy evaluation in the diagnosis of open angle glaucoma
}

This article was published in the following Dove Press journal:

Clinical Ophthalmology

24 August 2010

Number of times this article has been viewed

Joshua R Ehrlich

Nathan M Radcliffe

Department of Ophthalmology, Weill Cornell Medical College,

New York, NY, USA
Correspondence: Nathan Radcliffe

Weill Cornell Medical College, I305 York

Avenue, New York, NY 1002I, USA

$\mathrm{Tel}+\mathrm{I} 6469622020$

Fax + I 6469620603

Email nmr9003@med.cornell.edu
Purpose: To determine if clinical evaluation of parapapillary atrophy (PPA) significantly improves the ability to distinguish open-angle glaucoma (OAG) patients from glaucoma suspects.

Methods: Patients in this study were under evaluation for glaucoma and had open angles, at least one reliable 24-2 SITA-standard automatic perimetry, and digital stereophotographs of the optic disc. PPA was identified clinically as a parapapillary region of absent ( $\beta P P A)$ or hyper/hypopigmented ( $\alpha \mathrm{PPA}$ ) retinal pigment epithelium. A single masked observer evaluated photos for: vertical cup-to-disc ratio (CDR), clock hours of total and $\beta$ PPA, $\beta$ PPA as percentage width of the optic disc, presence or absence of $\beta$ PPA at each disc quadrant, and ordinal rating of total PPA. Generalized linear models were used to determine odds of an abnormal or borderline glaucoma hemifield test (GHT) as a function of PPA variables and covariates; model fit was assessed using the log-likelihood ratio test.

Results: Of 410 consecutive patients, 540 eyes (of 294 patients) met inclusion criteria. Mean age was greater among patients with abnormal compared with normal GHT $(P<0.001)$, but sex and race/ethnicity did not differ between groups $(P \geq 0.22)$. Age, central corneal thickness (CCT) and CDR $(P \leq 0.006)$, but not intraocular pressure (IOP) $(P=0.71)$, were significant univariable predictors of the odds of an abnormal GHT. All PPA parameters significantly predicted GHT $(P \leq 0.03)$, except presence of temporal $\beta$ PPA $(P=0.25)$. Adjustment for age, CCT, IOP, and CDR reduced the association between PPA and GHT, and model fit was not greatly improved by addition of PPA variables.

Conclusions: Addition of most PPA parameters to a model already containing commonly assessed variables including age, CCT, IOP, and CDR does not significantly improve the ability to distinguish OAG patients from glaucoma suspects.

Keywords: glaucoma, visual fields, parapapillary atrophy, optic nerve

\section{Introduction}

Glaucomatous optic neuropathy may be evaluated by direct or indirect ophthalmoscopy of the optic nerve, optic nerve photography, or computerized imaging technologies. Clinical features of glaucomatous optic neuropathy include atrophy of the retinal nerve fiber layer, focal or diffuse narrowing of the neuroretinal rim, optic disc splinter hemorrhage $(\mathrm{DH})$ and parapapillary atrophy (PPA). ${ }^{1-3}$

PPA is a form of outer retinal atrophy that abuts the optic disc and can be divided into alpha $(\alpha)$ and beta $(\beta)$ zones. ${ }^{4-6}$ Because this atrophy most often lies adjacent to but does not completely surround the nerve, the term parapapillary may be preferable to peripapillary atrophy, though they are used interchangeably in the literature. In $\beta$ PPA the sclera and large choroidal vessels are visible, as the retinal pigment epithelium 
(RPE) and most of the photoreceptors are absent. ${ }^{4,5}$ In $\alpha$ PPA, there is an irregular arrangement of RPE cells that can result clinically in both hypo- and hyperpigmentation. The $\alpha$ zone is more peripheral than the $\beta$ zone when both are present.

Of note, there are no imaging devices to provide automated assessment of DH or PPA, which at the present time are assessed either by patient examination or by photographic interpretation. Interestingly, several studies addressing the topic have found that PPA and DH tend to occur together in eyes and, additionally, tend to occur in the same regions of the eye, leading to the possibility that PPA may be useful as an indicator of increased likelihood of prior, present, or future disc hemorrhage..$^{7-12}$ Because $\beta$ PPA is present in 15\%-20\% of normal eyes, its presence is less specific for glaucoma than $\mathrm{DH}$, which occurs only in $0.6 \%$ of healthy eyes. ${ }^{11,13}$ Given that DH is transient, lasting weeks to months, and that PPA is stable and progressive, it may be advantageous to rely on PPA parameters for glaucoma diagnosis and monitoring. ${ }^{8,12}$

$\alpha$ PPA and $\beta$ PPA have been evaluated in glaucoma using quantitative analysis of optic nerve photographs (morphometry) typically by manually outlining and measuring the area of PPA using a slide projector, imaging processing software, or with confocal scanning laser ophthalmoscopy. ${ }^{5-7,14-20}$ Both $\alpha$ PPA and $\beta P P A$ are larger and occur more frequently in eyes with glaucoma than in normal eyes, though $\beta P P A$ is more specific for glaucoma., ${ }^{5,14,15}$ Using these morphometric techniques, PPA has been reported to be helpful in differentiating between normal and glaucomatous eyes. 5,6,14,15,21-24

While many morphometric investigations of PPA in glaucomatous and normal eyes have reported significant differences between these 2 groups, there is a paucity of information on how clinical evaluation of PPA may guide the clinician in the diagnosis of open-angle glaucoma (OAG). Additionally, it is difficult clinically to estimate quantitative PPA parameters, such as area of PPA, due to its heterogenous shape. Despite this, in a clinical assessment using direct ophthalmoscopy alone, information including the PPA circumferential extent and amount of neuroretinal rim narrowing increased the sensitivity and specificity for detection of glaucomatous visual field loss. ${ }^{1}$ However, some previous evaluations of PPA did not consider potential confounding variables such as age or intraocular pressure (IOP) that are typically available to the clinician at the time of diagnosis. ${ }^{1,5,6,14}$ In order to determine the clinical utility of PPA evaluation in glaucoma assessment, we developed a clinical PPA grading system and conducted this investigation to determine if clinical PPA assessment could improve the prediction of glaucomatous visual field loss beyond that of standard clinical variables such as age, central corneal thickness (CCT), IOP and vertical cup-to-disc ratio (CDR).

\section{Patients and methods}

This retrospective cross-sectional study was approved by the Institutional Review Board at Weill Cornell Medical College and New York Presbyterian Hospital. Patients under 18 years of age or with a history of corneal disease or keratorefractive surgery were excluded, as were patients with visually significant cataract (visual acuity $<20 / 40$ ), inflammatory eye disease, ocular trauma and non-glaucomatous optic neuropathy, or visual field loss.

Included patients were under evaluation for glaucoma and had documented open angles on examination. All patients had at least one reliable (fixation loss $<33 \%$; false-positive rate $<33 \%$; false-negative rate $<33 \%$ ) and repeatable $24-2$ SITA-standard automatic perimetry with the Humphrey Field Analyzer II (Carl Zeiss Meditec, Dublin, CA, USA). Patients were classified as having $\mathrm{OAG}$ if the glaucoma hemifield test (GHT) was borderline or outside normal limits; patients were classified as glaucoma suspects if the GHT was within normal limits. All patients had also undergone optic nerve digital stereophotography of acceptable or excellent quality with a Topcon TRC 50EX Retinal Camera (Topcon Co., Tokyo, Japan) within 18 months of inclusion. Demographic and clinical data including age, sex, self-reported race/ethnicity, CCT, and IOP on the day of examination were obtained by chart review.

One reviewer (NMR) evaluated optic nerve stereophotographs in a masked fashion using stereoscopic viewing lenses (Figure 1). CDR was recorded. PPA was identified clinically as a parapapillary region of absent ( $\beta P P A)$ or hyper/hypopigmented ( $\alpha$ PPA) retinal pigment epithelium. The circumferential extent of total (both $\alpha$ and $\beta$ ) PPA and $\beta P P A$ were recorded in clock hours; the maximal radial $\beta P P A$ extent (width) was estimated as a percentage of maximal optic disc dimensions (regardless of absolute optic disc size); the presence or absence of $\beta$ PPA was assessed at each optic nerve head quadrant; and an ordinal rating (0-3) of total PPA was assigned as follows: grade 0 represented no clinically identifiable $\alpha$ PPA or $\beta$ PPA; grade 1 represented any level of $\alpha$ PPA only; grade 2 represented any level of $\alpha \mathrm{PPA}$ with mild and moderate $\beta \mathrm{PPA}$; and grade 3 represented $\beta$ PPA that was extensive either in circumference (12 clock hours) or volume (larger in area than the optic disc itself). 


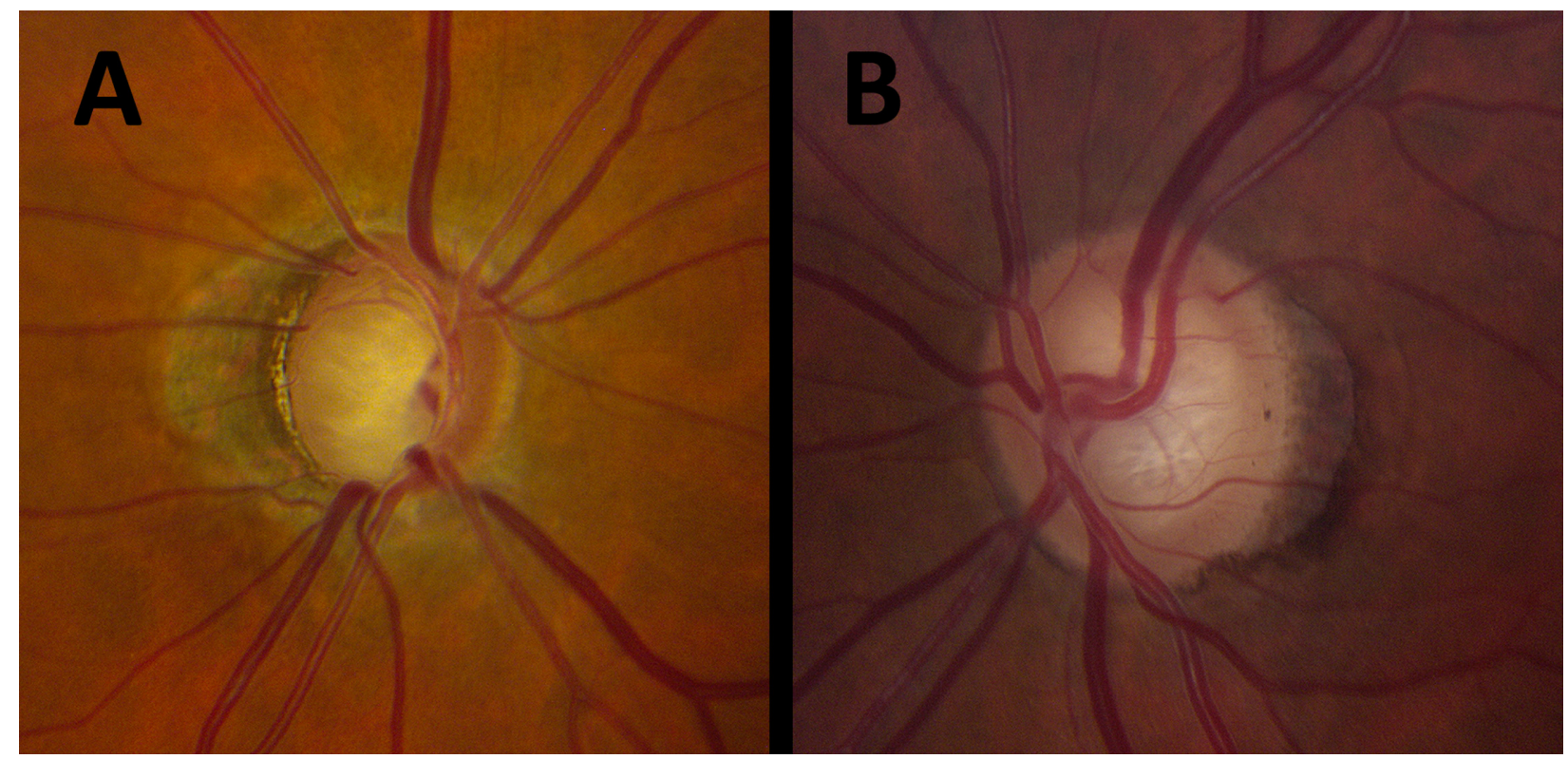

Figure I Clinical parapapillary atrophy (PPA) evaluation of 2 patients. A) Total PPA clock hours, 12 ; $\beta$ PPA clock hours, 5 ; $\beta$ PPA as percentage of disc, $60 \%$; $\beta$ PPA present, temporal; ordinal rating of total PPA, 3. B) Total PPA clock hours, 8; $\beta$ PPA clock hours, 4; $\beta$ PPA as percentage of disc, $20 \%$; $\beta$ PPA present, temporal; ordinal rating of total PPA, 2.

Statistical analyses were performed using Stata 11/IC (StataCorp LP, College Station, TX, USA). Differences in characteristics between patients with normal and abnormal/borderline GHT were assessed using two-sample $t$-tests or the chi-squared test. Differences in quantity of PPA between groups were assessed using generalized estimating equations to control for the inter-eye correlation of individuals; differences in geographic distribution of PPA were tested with the chi-squared test; and the Kruskal-Wallis test was used to test for differences in ordinal PPA rating. Generalized linear models with robust standard errors adjusted for clustering by patient were fit with a logit link function. Odds ratios (ORs) of an abnormal/borderline GHT were estimated as a function of increasing PPA and covariates. The likelihoodratio test was used to calculate the statistical improvement in model fit when PPA parameters were added to models already containing age, CCT, IOP, and CDR. All statistical tests were 2 -sided with a 0.05 level of significance.

\section{Results}

Patient characteristics, including PPA parameters, are presented in Table 1. Patients with OAG were significantly older than glaucoma suspects ( 61.9 versus 55.3 years; $P<0.001$ ), and there was no difference in sex or ethnic/racial distribution between groups $(P \geq 0.22)$. Patients with OAG had significantly greater PPA than glaucoma suspects for all PPA variables measured $(P \leq 0.02)$ except for presence of temporal PPA $(P=0.25)$.
Univariable logistic models were fit to predict the change in odds of OAG as a function of increasing age, CCT, IOP, and $\mathrm{CDR}$ (Table 2). Increasing age $(\mathrm{OR}=1.4$ per 10 years, 95\% confidence interval (CI) 1.2, 1.6, $P<0.001)$ and CDR $(\mathrm{OR}=1.3$ per 0.1 units, $95 \%$ CI $1.2,1.4, P<0.001)$ but not IOP $(P=0.71)$ were significantly associated with greater odds of OAG. Likewise, increasing CCT was significantly associated with decreased odds of an $\mathrm{OAG}(\mathrm{OR}=0.9$ per $10 \mu \mathrm{m}, 95 \%$ CI $0.9,1.0, P<0.001$ ).

Univariable logistic models were also fit to determine the association of PPA variables with OAG (Table 3A). Again, an increase in each of the PPA parameters $(P \leq 0.03)$, except for presence of temporal $\beta$ PPA $(P=0.30)$, was found to be significantly associated with an increase in the odds of OAG.

Each PPA variable was then added to a logistic model already containing age, CCT, IOP, and CDR, and the odds of OAG as a function of increasing PPA was determined when adjusting for covariates (Table 3B). With adjustment for age, CCT, IOP, and CDR, the magnitude of association between nasal $\beta P P A$ and OAG increased compared with the crude association and trended toward statistical significance $(\mathrm{OR}=1.6,95 \% \mathrm{CI} 1.0,2.7, P=0.06)$. However, after adjustment for clinical covariates no other PPA variables were statistically significant predictors of the odds of OAG $(P \geq 0.10)$.

Finally, the likelihood-ratio test was used to calculate the change in statistical fit of the model containing age, CCT, 
Table I Patient and parapapillary atrophy characteristics

\begin{tabular}{|c|c|c|c|}
\hline & $\begin{array}{l}\text { Glaucoma } \\
\text { suspects }\end{array}$ & OAG & $P$-value \\
\hline Number eyes (patients) & $229(157)$ & $311(209)$ & - \\
\hline Age (years) & $55.3( \pm 5.2)$ & $61.9( \pm 14.2)$ & $<0.001$ \\
\hline Female (\%) & 64.1 & 66.0 & 0.76 \\
\hline \multicolumn{4}{|l|}{ Race/ethnicity (\%) } \\
\hline Caucasian & 34.6 & 26.3 & 0.22 \\
\hline African-American & 20.5 & 30.6 & \\
\hline Hispanic & 29.5 & 32.1 & \\
\hline Other race/ethnicity & 15.4 & 11.0 & \\
\hline Clock hours total PPA & $5.1( \pm 3.5)$ & $6.7( \pm 3.7)$ & $<0.001$ \\
\hline Clock hours $\beta$ PPA & $3.7( \pm 3.5)$ & $5.2( \pm 4.3)$ & $<0.001$ \\
\hline Percent width $\beta$ PPA & I5.I ( $( \pm 22.0)$ & $21.0( \pm 28.2)$ & 0.02 \\
\hline \multirow{2}{*}{\multicolumn{4}{|c|}{$\begin{array}{l}\text { Percent eyes with } \beta \text { PPA } \\
\text { at disc quadrant: }\end{array}$}} \\
\hline & & & \\
\hline Temporal (\%) & 44.5 & 49.5 & 0.25 \\
\hline Inferior (\%) & 24.9 & 34.4 & 0.02 \\
\hline Nasal (\%) & 18.3 & 34.7 & $<0.001$ \\
\hline Superior (\%) & 13.5 & 24.1 & 0.002 \\
\hline \multirow{2}{*}{\multicolumn{4}{|c|}{$\begin{array}{l}\text { Percent eyes with PPA } \\
\text { ordinal rating: }\end{array}$}} \\
\hline & & & \\
\hline $0(\%)$ & 7.4 & 5.5 & $<0.001$ \\
\hline I (\%) & 54.2 & 38.1 & \\
\hline $2(\%)$ & 31.9 & 39.4 & \\
\hline $3(\%)$ & 6.6 & I7.I & \\
\hline
\end{tabular}

Abbreviations: OAG, open-angle glaucoma; PPA, parapapillary atrophy.

IOP, CDR, and a single PPA variable compared with the same model without a PPA variable (Table 3B). Inclusion of the nasal $\beta P P A$ variable significantly improved model fit $\left(\mathrm{X}^{2}[1]=4.5, P=0.03\right)$. Other PPA variables did not have a statistically significant impact on the fit of the logistic model $(P \geq 0.06)$. While the results of the likelihood-ratio test for total PPA clock hours $\left(\mathrm{X}^{2}[1]=3.6, P=0.06\right)$ and ordinal rating of PPA $\left(\mathrm{X}^{2}[3]=6.8, P=0.08\right)$ trended toward statistical significance, these variables were not significant independent predictors of OAG in their respective multivariable models. The logistic model containing age, CCT, IOP, and CDR correctly predicted the OAG status of $63.2 \%$ of eyes. Inclusion of total PPA clock hours in this model improved prediction of OAG status more than other PPA variables,

Table 2 Simple logistic models: odds of open-angle glaucoma as a function of common clinical variables

\begin{tabular}{lll}
\hline & OR (95\% Cl) & P-value \\
\hline Age (per I0 years) & I.4 (I.2, I.6) & $<0.001$ \\
CCT (per I0 $\mu \mathrm{m})$ & $0.9(0.9,1.0)$ & 0.006 \\
IOPa (per I mm Hg) & $1.0(1.0,1.0)$ & 0.71 \\
CDR (per 0.I units) & $1.3(1.2,1.4)$ & $<0.001$ \\
\hline
\end{tabular}

aOP values were with treatment in $59 \%$ of patients classified as OAG.

Abbreviations: CCT, central corneal thickness; IOP, intraocular pressure; CDR, vertical cup-to-disc ratio. and the percentage of eyes correctly classified increased by $1.2 \%$ to a total of $64.4 \%$.

\section{Discussion}

Past investigations have demonstrated a strong association between PPA and glaucoma. ${ }^{5-7,14-17,25-28}$ The purpose of the current investigation was to determine if the clinician could utilize this association in the evaluation of glaucoma patients using visual inspection only. In this investigation, using our clinical grading scale, we replicated trends in the spatial and quantitative distribution of PPA that have been reported among patients with and without glaucoma. . $^{614,15,29}$ While PPA variables were, on their own, significantly predictive of the odds of OAG, this association was greatly attenuated by adjustment for 4 variables that comprise part of a typical glaucoma evaluation: age, CCT, IOP, and CDR. Furthermore, when values for these covariates were already known, modeling of the odds of OAG was not greatly improved by the consideration of PPA variables. This suggests that in clinically evaluating and diagnosing glaucoma there may be little incremental value to assessing PPA.

In the current study, patients with OAG had greater PPA that glaucoma suspects for every measure of PPA that was considered (though the difference was not statistically significant for $\beta$ PPA of the temporal quadrant). Past studies have shown that $\beta$ PPA tends to be larger in areas where the neuroretinal rim is focally narrow. ${ }^{14}$ Also, as measured with planimetry, the spatial distribution of PPA differs in glaucoma, with PPA being present nasally in 5\%-9\% of normal patients and $21 \%-38 \%$ of glaucoma patients. ${ }^{6,14,15}$ A similar trend was confirmed between patients with $\mathrm{OAG}$ and glaucoma suspects in the current study. However, the existence of nasal $\beta$ PPA among 34.7\% of OAG patients and only $18.3 \%$ of suspects indicates that nasal $\beta$ PPA is not a sensitive predictor of disease. Past investigations have also demonstrated that PPA is most commonly located temporally, followed by inferotemporally and then superotemporally. ${ }^{29}$ In the present study, $\beta$ PPA was most commonly located temporally among both OAG patients and glaucoma suspects.

In a study by Jonas and colleagues, the investigators sought to determine which features of the optic disc best distinguished normal and glaucomatous patients. ${ }^{20}$ The authors found that size of $\alpha$ and $\beta$ zone PPA, assessed using planimetric techniques, were among the least useful optic disc characteristics for differentiating normal subjects from subjects with either preperimetric or perimetric glaucoma. The variables that consistently offered the greatest diagnostic 
Table 3 Simple and multiple logistic models: odds of open-angle glaucoma as a function of parapapillary atrophy (PPA) variables

\begin{tabular}{|c|c|c|c|c|c|}
\hline \multicolumn{3}{|c|}{ A. Simple logistic models } & \multicolumn{3}{|c|}{ B. Adjusted models and model fit } \\
\hline & $\begin{array}{l}\text { Crude } \\
\text { OR }(95 \% \mathrm{CI})\end{array}$ & $P$-value & $\begin{array}{l}\text { Adjusted } \\
\text { OR }^{\mathrm{a}}(95 \% \mathrm{Cl})\end{array}$ & $P$-value & $\begin{array}{l}\text { Likelihood-ratio } \\
\text { test } P \text {-value }\left(\mathbf{X}^{2}\right)\end{array}$ \\
\hline $\begin{array}{l}\text { Clock hours total PPA } \\
\text { (per } 3 \text { hours) }\end{array}$ & $1.4(1.2,1.7)$ & $<0.001$ & $1.2(1.0,1.4)$ & 0.10 & $0.06(3.6)$ \\
\hline $\begin{array}{l}\text { Clock hours } \beta \text { PPA } \\
\text { (per } 3 \text { hours) }\end{array}$ & $1.4(1.2,1.6)$ & $<0.001$ & I.I $(0.9,1.3)$ & 0.20 & $0.16(2.0)$ \\
\hline Nasal $\beta$ PPA & I.4 (I.5, 3.7) & $<0.001$ & I.6 (I.0, 2.7) & 0.06 & $0.03(4.5)$ \\
\hline Inferior $\beta$ PPA & $1.6(1.0,2.4)$ & 0.03 & I.I $(0.7,1.7)$ & 0.70 & $0.65(0.2)$ \\
\hline Temporal $\beta$ PPA & $1.2(0.8,1.8)$ & 0.30 & $0.9(0.6,1.3)$ & 0.60 & $0.49(0.5)$ \\
\hline Superior $\beta$ PPA & $2.0(1.2,3.4)$ & 0.006 & I.2 $(0.7,2.1)$ & 0.50 & $0.5 \mathrm{I}(0.5)$ \\
\hline $\begin{array}{l}\text { Ordinal rating total PPA } \\
\text { (reference: rating }=0 \text { ) }\end{array}$ & & & & & \\
\hline i & $1.0(0.4,2.1)$ & 0.90 & $0.8(0.4,1.7)$ & 0.50 & $0.08(6.8)$ \\
\hline 2 & $1.7(0.7,3.8)$ & 0.20 & I.I $(0.5,2.6)$ & 0.70 & \\
\hline 3 & $3.5(1.4,9.1)$ & 0.009 & $1.6(0.6,4.6)$ & 0.30 & \\
\hline
\end{tabular}

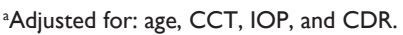

power in the study by Jonas et al were: CDR, neuroretinal rim area, rim-to-disc area and cup-to-disc area. ${ }^{20}$ While these findings largely agree with results from the current study, the current study did not morphometrically investigate optic disc parameters as was done by Jonas et al. Our investigation more specifically addressed the incremental importance of PPA variables, since in nearly all instances the clinician will have knowledge of a patient's age, CCT, IOP, and some measurement of CDR. Like Jonas and colleagues, we determined that PPA variables are not the most important clinical variables for distinguishing glaucomatous and nonglaucomatous patients.

The present study also has the advantage of utilizing a multivariable technique that allows for outcomes to be modeled as a function of multiple variables, as often occurs in the clinical setting. In this study, we considered a model that contained four standard clinical glaucoma variables (age, CCT, IOP, and CDR) with and without the addition of PPA variables. The addition of most PPA variables to this model resulted in little incremental improvement in the modeling of our data. This suggests that the more parsimonious model - the model without PPA - more appropriately represents these data.

A growing literature suggests that PPA may be more useful for evaluating progression than for detecting glaucoma. ${ }^{16-18,25}$ Studies have shown that PPA increases in size as glaucoma progresses and that it is not specific to the mechanism of glaucoma. ${ }^{16-18,22,25}$ In one report of eyes with progressive cupping, the area of PPA enlarged in 64\%, as opposed to $17 \%$ of eyes with glaucoma that did not have progressive cupping. ${ }^{16}$ Teng and colleagues showed that over a period of 3 years, glaucomatous eyes with $\beta$ zone PPA were more likely to show evidence of visual field progression and that a greater area of $\beta$ PPA was predictive of more rapid progression. As in the present study, Teng et al found that CCT was significantly associated with PPA. However, the association between visual field progression and presence of $\beta$ PPA persisted in a multivariable model controlling for baseline demographic and ocular characeristics. ${ }^{25}$ Likewise, Jonas et al found that the area of $\beta$ PPA was significantly larger among patients with progressive disease and that progression was associated with age, and the area of $\beta$ PPA and the neuroretinal rim. ${ }^{17,18}$ However, in a study of ocular hypertensives Quigley and colleagues did not find a significant difference in the prevalence of PPA between patients with and without progressive glaucoma. ${ }^{30}$

The current investigation was retrospective in nature so its results cannot be extrapolated to determine risk or future odds of glaucoma. It is possible that patients with normal visual fields (glaucoma suspects) considered in the study might have had pre-perimetric glaucoma, and some of the glaucoma suspects considered might have been referred for evaluation in part based upon the presence of PPA. However, both of the above limitations are commonly encountered in clinical glaucoma management and may actually add to the relevance of this work. This study is less quantitative than past studies that have used planimetric measurement of PPA. However, the clinical grading system that was developed for this study was designed to more closely resemble the sort of evaluation routinely performed in a clinical glaucoma examination. Notwithstanding, by assessing the additional benefit conferred by inclusion of PPA evaluation as part of 
a standard glaucoma exam, this investigation contributes to the understanding of the association between PPA and $\mathrm{OAG}$.

\section{Disclosure}

The authors report no conflicts of interest in this work, which was partially supported by a grant from the American Glaucoma Society.

\section{References}

1. Harper R, Reeves B. The sensitivity and specificity of direct ophthalmoscopic optic disc assessment in screening for glaucoma: a multivariate analysis. Graefes Arch Clin Exp Ophthalmol. 2000;238(12):949-955.

2. Theodossiades J, Murdoch I. What optic disc parameters are most accurately assessed using the direct ophthalmoscope? Eye (Lond). 2001;15(Pt 3):283-287.

3. Jonas JB, Budde WM, Panda-Jonas S. Ophthalmoscopic evaluation of the parapapillary region of the optic nerve head. Klin Oczna. 2004; 106 Suppl 1-2:279-289.

4. Kubota T, Jonas JB, Naumann GO. Direct clinico-histological correlation of parapapillary chorioretinal atrophy. $\mathrm{Br} J$ Ophthalmol. 1993;77(2):103-106.

5. Jonas JB, Naumann GO. Parapapillary chorioretinal atrophy in normal and glaucoma eyes. II. Correlations. Invest Ophthalmol Vis Sci. 1989;30(5):919-926.

6. Jonas JB, Nguyen XN, Gusek GC, Naumann GO. Parapapillary chorioretinal atrophy in normal and glaucoma eyes. I. Morphometric data. Invest Ophthalmol Vis Sci. 1989;30(5):908-918.

7. Hayakawa T, Sugiyama K, Tomita G, et al. Correlation of the peripapillary atrophy area with optic disc cupping and disc hemorrhage. J Glaucoma. 1998;7(5):306-311.

8. Radcliffe NM, Liebmann JM, Rozenbaum I, et al. Anatomic relationships between disc hemorrhage and parapapillary atrophy. $\mathrm{Am} \mathrm{J}$ Ophthalmol. 2008;146(5):735-740.

9. Ahn JK, Kang JH, Park KH. Correlation between a disc hemorrhage and peripapillary atrophy in glaucoma patients with a unilateral disc hemorrhage. J Glaucoma. 2004;13(1):9-14.

10. Jonas JB, Martus P, Budde WM. Inter-eye differences in chronic open-angle glaucoma patients with unilateral disc hemorrhages. Ophthalmology. 2002;109(11):2078-2083.

11. Sugiyama K, Tomita G, Kawase K, et al. Disc hemorrhage and peripapillary atrophy in apparently healthy subjects. Acta Ophthalmol Scand. 1999;77(2):139-142.

12. Law SK, Choe R, Caprioli J. Optic disk characteristics before the occurrence of disk hemorrhage in glaucoma patients. Am J Ophthalmol. 2001;132(3):411-413.

13. Budenz DL, Anderson DR, Feuer WJ, et al. Detection and prognostic significance of optic disc hemorrhages during the Ocular Hypertension Treatment Study. Ophthalmology. 2006;113(12):2137-2143.
14. Uhm KB, Lee DY, Kim JT, Hong C. Peripapillary atrophy in normal and primary open-angle glaucoma. Korean J Ophthalmol. 1998;12(1): $37-50$.

15. Xu L, Wang Y, Yang H, Jonas JB. Differences in parapapillary atrophy between glaucomatous and normal eyes: the Beijing Eye Study. Am J Ophthalmol. 2007;144(4):541-546.

16. Uchida $\mathrm{H}$. Increasing peripapillary atrophy is associated with progressive glaucoma. Ophthalmology. 1998;105(8):1541-1545.

17. Jonas JB. Predictive factors of the optic nerve head for development or progression of glaucomatous visual field loss. Invest Ophthalmol Vis Sci. 2004;45(8):2613-2618

18. Jonas JB, Martus P, Budde WM, Jünemann A, Hayler J. Small neuroretinal rim and large parapapillary atrophy as predictive factors for progression of glaucomatous optic neuropathy. Ophthalmology. 2002; 109(8):1561-1567.

19. Kwon YH, Kim YI, Pereira MLM, et al. Rate of optic disc cup progression in treated primary open-angle glaucoma. J Glaucoma. 2003;12(5): 409-416.

20. Jonas JB, Bergua A, Schmitz-Valckenberg P, Papastathopoulos KI, Budde WM. Ranking of optic disc variables for detection of glaucomatous optic nerve damage. Invest Ophthalmol Vis Sci. 2000;41(7): 1764-1773.

21. Wilensky JT, Kolker AE. Peripapillary changes in glaucoma. Am J Ophthalmol. 1976;81(3):341-345.

22. Rockwood EJ, Anderson DR. Acquired peripapillary changes and progression in glaucoma. Graefes Arch Clin Exp Ophthalmol. 1988;226(6): 510-515.

23. Jonas JB. Clinical implications of peripapillary atrophy in glaucoma. Curr Opin Ophthalmol. 2005;16(2):84-88.

24. Park KH, Park SJ, Lee YJ, Kim JY, Caprioli J. Ability of peripapillary atrophy parameters to differentiate normal-tension glaucoma from glaucomalike disk. J Glaucoma. 2001;10(2):95-101.

25. Teng CC, de Moraes CG, Prata TS, Tello C, Ritch R, Liebmann JM. Beta-Zone parapapillary atrophy and the velocity of glaucoma progression. Ophthalmology. 2010;117(5):909-915.

26. Kawano J, Tomidokoro A, Mayama C, et al. Correlation between hemifield visual field damage and corresponding parapapillary atrophy in normal-tension glaucoma. Am J Ophthalmol. 2006;142(1):40-45.

27. Tezel G, Kolker AE, Kass MA, et al. Parapapillary chorioretinal atrophy in patients with ocular hypertension. I. An evaluation as a predictive factor for the development of glaucomatous damage. Arch Ophthalmol. 1997;115(12):1503-1508.

28. Tezel G, Kolker AE, Wax MB, et al. Parapapillary chorioretinal atrophy in patients with ocular hypertension. II. An evaluation of progressive changes. Arch Ophthalmol. 1997;115(12):1509-1514.

29. Heltzer JM. Progression of peripapillary atrophy. Ophthalmology. 1999;106(5):857.

30. Quigley HA, Katz J, Derick RJ, Gilbert D, Sommer A. An evaluation of optic disc and nerve fiber layer examinations in monitoring progression of early glaucoma damage. Ophthalmology. 1992;99(1):19-28.
Clinical Ophthalmology

\section{Publish your work in this journal}

Clinical Ophthalmology is an international, peer-reviewed journal covering all subspecialties within ophthalmology. Key topics include: Optometry; Visual science; Pharmacology and drug therapy in eye diseases; Basic Sciences; Primary and Secondary eye care; Patient Safety and Quality of Care Improvements. This journal is indexed on Submit your manuscript here: http://www.dovepress.com/clinical-ophthalmology-journal

\section{Dovepress}

PubMed Central and CAS, and is the official journal of The Society of Clinical Ophthalmology (SCO). The manuscript management system is completely online and includes a very quick and fair peer-review system, which is all easy to use. Visit http://www.dovepress.com/ testimonials.php to read real quotes from published authors. 